\title{
Asymmetric Epoxidation of Cyclic Enones under Chiral Phase Transfer Conditions
}

\author{
Naomichi BABA, Jun'ichi OdA and Mamoru KaWAGUCHI* \\ Institute for Chemical Research, Kyoto University, \\ Uji, Kyoto 611, Japan \\ *International Reagent Corporation, 3-2, 4-chome, Takatsukadai, \\ Nishi-ku, Kobe 673-02, Japan
}

Received July 10, 1986

\begin{abstract}
Asymmetric epoxidation of cyclic enones was performed with 9-alkylfluorenyl peroxides under two-phase conditions in the presence of novel phase transfer catalysts derived from cinchona alkaloids. The observed enantiomeric excess ranged between $30 \sim 63 \%$, from which it is shown that the fluorenyl group had a remarkable effect on the enhancement of enantioselectivity.
\end{abstract}

Optically active epoxides are an important class of starting material or an intermediate in organic syntheses, and their method of preparation has been extensively studied. ${ }^{1)}$ However, highly enantioselective asymmetric epoxidation has remained the way for this development, except for the Sharpless epoxidation of allylic alcohols.

Asymmetric epoxidations of enones with hydrogen peroxide or alkyl hydroperoxide under chiral phase transfer conditions have been

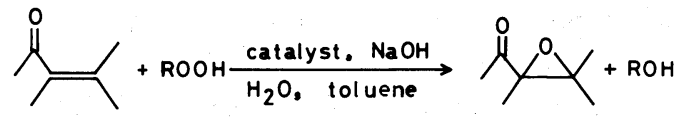

developed by Wynberg, ${ }^{2)}$ Colona $^{3)}$ and Mazaleyrat ${ }^{4)}$. Although the enantiomeric excess $(\%$ e.e. $)$ reported by the authors were satisfactory only in the epoxidation of benzalacetophenone, such reactions constitute a very important example to promote catalytic asymmetric epoxidation of synthetically useful substrates with high enantioselectivity. From this view, the present study was undertaken to further this system with regard to structural variation of the epoxidizing agent (alkyl peroxide) and phase transfer catalyst (quaternary ammonium salt).

\section{RESULTS AND DISCUSSION}

From our stereochemical studies of an NADH model reaction, ${ }^{5)}$ it was noted that polar functional groups, a rigid framework and $C_{2}$-symmetry of the reactant molecules were very important for a high degree of chiral discrimination. Thus prepared in the present study were novel phase transfer catalysts $(\mathbf{5}, \mathbf{6}$ and 7), which were so designed to have $C_{2}$ symmetry in the former two and a fluorenyl group to afford a rigid steric framework in the last one. Also, each of them has a hydroxyl group as a polar functional ligand, which was pointed out by Wynberg ${ }^{6)}$ to be great importance for higher selectivity. As epoxidizing agents, $8 \sim \mathbf{1 2}^{7)}$ were provided in the present study. Here, 8 and 9 are supposed to have conformationally mobile structure, whereas, $10 \sim 12$ have rigid framework of a fluorenyl nucleus. Consequently, it is of interest to see how these structural differences in the catalyst and epoxidizing agent reflect on the enantioselectivity for asymmetric epoxidation.

The epoxidations of $1 \sim 4$ were conducted under two-phase conditions (toluene-water), ${ }^{8)}$ in the presence of a small amount of sodium hydroxide at between $-10^{\circ} \mathrm{C}$ and room temperature. After the reaction, the working-up procedure and determination of the $\%$ e.e. were 

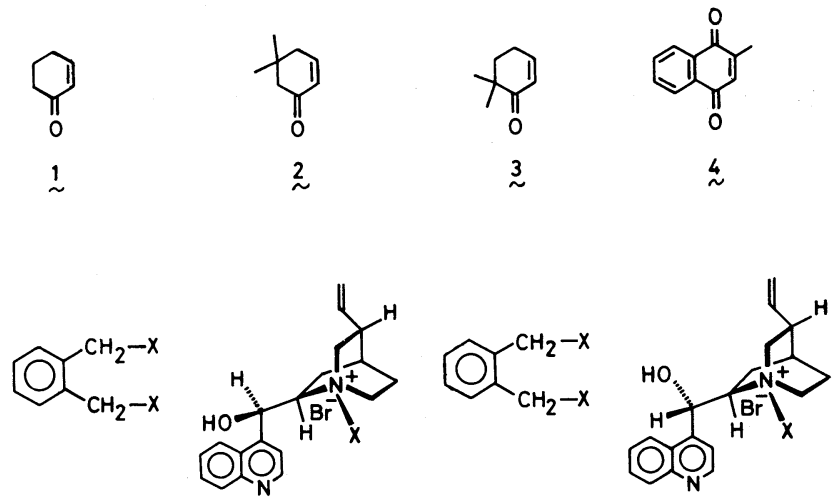

$\stackrel{5}{\sim}$

$\underset{\sim}{6}$

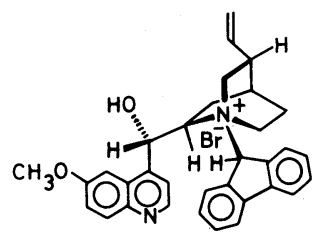

$\stackrel{7}{\sim}$

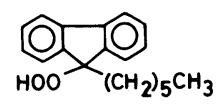

10

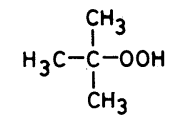

$\stackrel{8}{\sim}$

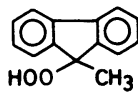

$\stackrel{11}{m}$
$\mathrm{CH}_{3}\left(\mathrm{CH}_{2}\right)_{5} \mathrm{OOH}$

$\stackrel{9}{2}$

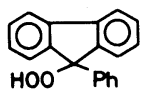

12 performed as described in the experimental section. The catalytic efficiency, and the chemical and optical yields are given in Table I, in addition to the reaction conditions. As run 1 shows, the epoxidation of $\mathbf{1}$ by tert-butyl hydroperoxide in the presence of the catalyst 5 and sodium hydroxide afforded the corresponding oxirane in $33 \%$ e.e. With a long-chain primary hydroperoxide (9), ${ }^{9)}$ the e.e. was only $4 \%$ (run 2 ). On the other hand, when fluorenyl peroxides $(\mathbf{1 0} \sim 12)$ wee used, the selectivity was remarkably improved to $61 \%$ e.e. with $\mathbf{1 0}$ (run 3), 63\%e.e. with 11 (run 6) and $38 \%$ e.e. with 12 (run 7). This constitute an interesting example in which the stereoselectivity of asymmetric epoxidation depends strongly on the structure of the oxidizing agent.

In the epoxidation of the same substrate by use of another $C_{2}$-symmetric catalyst (6) from (-)-cinchonidine, fluorenyl peroxides showed higher enantioselectivity (runs 10 and 11) than with tert-butyl hydroperoxide (run 8) and hexyl peroxide (run 9). On the other hand, the configuration at the asymmetric centers of the epoxide were reversed from: $(2 S, 3 R)$ in runs $1 \sim 7$ with the catalyst 5 to $(2 R, 3 S)$ in runs $8 \sim 11$ with the catalyst 6 using the same peroxides. Since the difference between 5 and $\mathbf{6}$ is the configurational reversal alone at the asymmetric center bearing a hydroxyl group in the alkaloid moiety, such a change was found to reflect directly on the configuration of the epoxide product. Thus, the sense of chirality at the asymmetric carbon near the catalytic site (positively charged quinuclidine nitrogen) seems to be crucial in determining the product stereochemistry.

When the relative amount of catalyst to substrate $(\mathrm{mol} / \mathrm{mol})$ was reduced from 0.007 (run 3) to 0.001 (run 5), the e.e. dropped from 
Table I. Asymmetric Epoxidation of Cyclic Enones $(\mathbf{1} \sim 4)$ with Peroxides $(\mathbf{8} \sim 12)$ Under Phase Transfer Conditions ${ }^{a}$

\begin{tabular}{|c|c|c|c|c|c|c|c|c|c|c|}
\hline Run & Substrate & Catalyst & $\begin{array}{l}\text { Catalyst (mmol) } \\
\text { Substrate (mmol) }\end{array}$ & Peroxide & Base & $\begin{array}{l}\% \text { Chem. } \\
\text { yield }\end{array}$ & $\begin{array}{l}\% \text { Catalytic } \\
\text { efficiency }\end{array}$ & {$[\alpha]_{578} /^{o c}$} & $\%$ e.e. ${ }^{d}$ & Configuration \\
\hline 1 & 1 & 5 & 0.009 & 8 & $\mathrm{NaOH}$ & 94 & 10400 & -64.2 & 33 & $2 S, 3 R$ \\
\hline 2 & 1 & 5 & 0.013 & 9 & $\mathrm{NaOH}$ & 49 & 3800 & -7.6 & 4 & $2 S, 3 R$ \\
\hline 3 & 1 & 5 & 0.007 & 10 & $\mathrm{NaOH}$ & 78 & 11000 & -119.4 & 61 & $2 S, 3 R$ \\
\hline 4 & 1 & 5 & 0.02 & 10 & $\mathrm{NaOH}$ & 69 & 3400 & -85.5 & 44 & $2 S, 3 R$ \\
\hline 5 & 1 & 5 & 0.001 & 10 & $\mathrm{NaOH}$ & 72 & 30100 & -59.0 & 30 & $2 S, 3 R$ \\
\hline 6 & 1 & 5 & 0.004 & 11 & $\mathrm{NaOH}$ & 50 & 12500 & -122.7 & 63 & $2 S, 3 R$ \\
\hline 7 & 1 & 5 & 0.008 & 12 & $\mathrm{NaOH}$ & 50 & 6300 & -74.6 & 38 & $2 S, 3 R$ \\
\hline 8 & 1 & 6 & 0.007 & 8 & $\mathrm{NaOH}$ & 86 & 12200 & +25.9 & 13 & $2 R, 3 S$ \\
\hline 9 & 1 & 6 & 0.007 & 9 & $\mathrm{NaOH}$ & 82 & 11700 & +33.4 & 17 & $2 R, 3 S$ \\
\hline 10 & 1 & 6 & 0.004 & 10 & $\mathrm{NaOH}$ & 75 & 18800 & +68.0 & 35 & $2 R, 3 S$ \\
\hline 11 & 1 & 6 & 0.007 & 11 & $\mathrm{NaOH}$ & 84 & 12000 & +96.7 & 50 & $2 R, 3 S$ \\
\hline 12 & 1 & 7 & 0.02 & 8 & $\mathrm{NaOH}$ & 56 & 2800 & -119.6 & 61 & $2 S, 3 R$ \\
\hline 13 & 1 & 7 & 0.02 & 9 & $\mathrm{NaOH}$ & 69 & 3500 & -59.5 & 31 & $2 S, 3 R$ \\
\hline 14 & 1 & 7 & 0.02 & 10 & $\mathrm{NaOH}$ & 60 & 3000 & -114.4 & 59 & $2 S, 3 R$ \\
\hline 15 & 1 & 7 & 0.06 & $28 \% \mathrm{H}_{2} \mathrm{O}_{2}$ & $\mathrm{NaOH}$ & 49 & 800 & -0.4 & 0.2 & $2 S, 3 R$ \\
\hline 16 & 1 & 7 & 0.06 & $5 \% \mathrm{NaClO}$ & $\mathrm{NaOH}$ & 45 & 750 & 0 & - & - \\
\hline 17 & 1 & 7 & 0.02 & 8 & $\mathrm{RbOH}$ & 80 & 4000 & -26.1 & 1,3 & $2 S, 3 R$ \\
\hline 18 & 1 & 7 & 0.02 & 8 & $\mathrm{CsOH}$ & 90 & 4500 & -9.7 & 5 & $2 S, 3 R$ \\
\hline 19 & 1 & 7 & 0.02 & 8 & $\mathrm{KOH}$ & 65 & 3300 & -25.6 & 13 & $2 S, 3 R$ \\
\hline 20 & 1 & 7 & 0.02 & 8 & $\mathrm{LiOH}$ & 62 & 3100 & -113.1 & 58 & $2 S, 3 R$ \\
\hline 21 & 1 & 7 & 0.02 & 8 & $\mathrm{Ba}(\mathrm{OH})_{2}$ & 38 & 1600 & -74.1 & 38 & $2 S, 3 R$ \\
\hline 22 & 1 & 7 & 0.02 & 8 & $\mathrm{Ca}(\mathrm{OH})_{2}$ & 0 & - & - & - & - \\
\hline 23 & 2 & 7 & 0.07 & 8 & $\mathrm{NaOH}$ & $60^{e}$ & 830 & +25.2 & 45 & - \\
\hline 24 & 2 & 5 & 0.02 & 10 & $\mathrm{NaOH}$ & $100^{e}$ & 4800 & +24.5 & 44 & - \\
\hline 25 & 3 & 7 & 0.02 & 10 & $\mathrm{NaOH}$ & $100^{e}$ & 4800 & -13.6 & 14 & - \\
\hline 26 & 3 & 5 & 0.06 & 8 & $\mathrm{NaOH}$ & 73 & 1200 & -21.7 & 22 & - \\
\hline 27 & 4 & 5 & 0.002 & 8 & $\mathrm{NaOH}$ & 53 & 26500 & $+11.8^{f}$ & 10 & $2 S, 3 R$ \\
\hline 28 & 4 & 5 & 0.007 & 10 & $\mathrm{NaOH}$ & 60 & 8400 & $-16.6^{f}$ & 13 & $2 R, 3 S$ \\
\hline 29 & 4 & 7 & 0.02 & 8 & $\mathrm{NaOH}$ & 63 & 3100 & $+22.5^{f}$ & 18 & $2 S, 3 R$ \\
\hline
\end{tabular}

The reactions were carried out between $-10^{\circ} \mathrm{C}$ and room temperature for $6 \sim 28 \mathrm{hr}$ in toluene in the presence of a small amount of water. The reaction conditions were not optimized.

b $\%$ Catalytic efficiency $=\%$ chem. yield $\times$ substrate $(\mathrm{mmol}) /$ catalyst $(\mathrm{mmol})$.

c The rotations were measured in methylene chloride.

d Enantiomeric excesses were determined from their optical rotations. Cyclohexenone 2,3-epoxide, 5,5- and 6,6-dimethylcyclohexenone 2,3-epoxide: ref. 2b. Menadione 2,3-epoxide: S. Snatzke, H. Wynberg, B. Feringa, B. G. Marsman, B. Greydanus and H. Pluim, J. Org. Chem., 45, 4094 (1980).

e Conversion yield by VPC.

$f$ Optical rotations at $436 \mathrm{~nm}$. 
61 to $30 \%$. Even without the catalyst, this epoxidation reaction was found to proceed to some extent, which, of course, provided no optically active product. Therefore, if such an uncatalyzed reaction accompanies, the final e.e. should be reduced. By simple calculation, the contribution of the uncatalyzed pathway was roughly estimated as $17 \%$ for the reaction in run 3.

The fluorene nucleus which was thus proved to be effective for selectivity amplification was also introduced into quinine by quaternizing the quinuclidine nitrogen with 9-bromofluorene to give another chiral ammonium salt 7. By use of this catalyst and tertbutyl hydroperoxide, the substrate 1 was converted to the epoxide with $61 \%$ e.e. (run 12). A combination of the catalyst 7 and the peroxide 10 afforded the product with $59 \%$ e.e. (run 14 ). Thus, the fluorene nucleus was shown to be effective here too, when it was introduced into the phase transfer catalyst. On the other hand, with a long chain hydroperoxide $\mathbf{9}$, the selectivity decreased to $31 \%$ (run 13 ) in the presence of the same catalyst. This result as well as those in runs 2 and 9 indicate that at least a long-chain flexible hydroperoxide seems to be less effective for higher selectivity.

Several alkaline and alkaline earth metal hydroxides were examined (runs $17 \sim 22$ ) for activation of the hydroperoxides, and sodium and lithium hydroxide were found to be the best for selectivity (runs 12 and 20). Rubidium and cesium hydroxides were shown to be excellent bases for the epoxidation, but the e.e. of the products was low (runs 17 and 18).

The present system was applied to other cyclic enones (2, 3 and 4$)$. As shown in runs $23 \sim 29$, the selectivity was found to be rather moderate, and in the epoxidation of menadione (4, runs 27 and 28), the product configuration was reversed by changing the peroxide from 8 to 10. Although the observed $\%$ e.e. was higher than that reported by Wynberg et al., ${ }^{10)}$ the selectivity was unsatisfactory and some different hydroperoxide and/or phase transfer catalyst should be designed further.
Finally, the catalytic efficiency $(\%$ chem. yield $\times$ substrate $[\mathrm{mmol}] /$ catalyst $[\mathrm{mmol}])$ is given in the table as a rough estimation for each reaction. For example, $11,000 \%$ is shown in run 3 , from which it was realized that a catalyst molecule was recycled to produce about 110 molecules of the epoxide. This efficiency is satisfactory enough for our present purpose. In the other cases with low efficiency, these may be improved by optimizing the other reaction conditions.

In summary, asymmetric epoxidation of cyclic enones was performed with different peroxides and chiral phase transfer catalyst under two-phase conditions, from which it is shown that a fluorenyl group introduced into the peroxide or the catalyst had an outstanding effect on enhancing the stereoselectivity of epoxidation. Although the mechanism of the selectivity are unknown, the rigid and planar structure of the fluorenyl group might be of potential importance for stereochemical control of the one oxygen atom transfer. The present result suggests that a group effect of this kind can be applied to other stereoselective reactions as well.

\section{EXPERIMENTAL}

Optical rotations were taken on a Perkin-Elmer 241 polarimeter. VPC analyses and preparative VPC were on a Shimadzu GC-4CM with 5\%-XE-60 $\left(1 \mathrm{~m}, 120^{\circ} \mathrm{C}\right)$ and a Varian Aerograph Model 920 with 5\%-XE-60 (3m, $\left.170^{\circ} \mathrm{C}\right)$.

Quaternization of $(+)$-cinchonine with $\alpha, \alpha^{\prime}$-dibromo-oxylene. A mixture of $(+)$-cinchonine $(5.88 \mathrm{~g}, 10.0$ mmol) with $\alpha, \alpha^{\prime}$-dibromo-o-xylene $(2.64 \mathrm{~g}, 5.0 \mathrm{mmol})$ in a mixture of ethanol $(15 \mathrm{ml}), \mathrm{DMF}(18 \mathrm{ml})$ and chloroform $(5 \mathrm{ml})$ was refluxed for $7 \mathrm{hr}$. After cooling the reaction mixture to room temperature, an excess of acetonitrile and ether was added. The amorphous solid separated from the solution was filtered, washed with acetonitrile and dried over phosphorus pentoxide in vacuo at $95^{\circ} \mathrm{C}$. Chem. yield, $2.24 \mathrm{~g}(53 \%) . \mathrm{mp} 178 \sim 180^{\circ} \mathrm{C} . \quad[\alpha]_{\mathrm{D}}^{20}+271.1 \quad(c=0.128$, $\left.\mathrm{CH}_{3} \mathrm{OH}\right) . \mathrm{IR} v_{\max }^{\mathrm{KBr}} \mathrm{cm}^{-1}: 1590,1510,1460,1000,935,760$, 775. found: $\mathrm{C}, 60.42 ; \mathrm{H}, 6.35 ; \mathrm{N}, 6.22$. Calcd. for $\mathrm{C}_{46} \mathrm{H}_{52} \mathrm{~N}_{4} \mathrm{O}_{2} \mathrm{Br}_{2} \cdot 3 \mathrm{H}_{2} \mathrm{O}: \mathrm{C}, 60.90 ; \mathrm{H}, 6.44 ; \mathrm{N}, 6.22$.

Quaternization of (-)-cinchonidine with $\alpha, \alpha^{\prime}$-dibrom-oxylene. (-)-cinchonidine was quaternized with $\alpha, \alpha^{\prime}$ dibrom- $o$-xylene under the same conditions as just men- 
tioned. Chem. yield, $3.5 \mathrm{~g}(82 \%)$. This salt was recrystallized twice from ethanol and methanol-chloroform. $\mathrm{mp}$ $201 \sim 203^{\circ} \mathrm{C}$ (decomp.) $[\alpha]_{\mathrm{D}}^{30}-101.6^{\circ}(c=1: 12, \mathrm{DMF})$. IR $v_{\max }^{\mathrm{KBr}} \mathrm{cm}^{-1}: 1620,1510,1455,1160,1245,1230,1100,1035$, $850,780,750,740$. Found: C, 60.97; H, 6.03; N, 6.19. Calcd. for $\mathrm{C}_{46} \mathrm{H}_{52} \mathrm{~N}_{4} \mathrm{O}_{2} \mathrm{Br}_{2} \cdot 3 \mathrm{H}_{2} \mathrm{O}: \mathrm{C}, 60.90 ; \mathrm{H}, 6.44 ; \mathrm{N}$, 6.22 .

Quaternization of (-)-quinine with 9-bromofluorene. A solution of (-)-quinine $(2.00 \mathrm{~g}, 6.16 \mathrm{mmol})$ and 9-bromofluorene $(1.51 \mathrm{~g}, 6.16 \mathrm{mmol})$ in dry acetone $(55 \mathrm{ml})$ was refluxed for $45 \mathrm{hr}$. After cooling to room temperature, a small amount of ether was added to the reaction mixture until the solution became slightly turbid. The mixture was kept at ambient temperature overnight. The crystalline salt that separated from the solution was filtered, washed with acetone-ether $(2: 1)$ and dried over phosphorus pentoxide in vacuo at $90^{\circ} \mathrm{C}$. Chem. yield, $1.53 \mathrm{~g}\left(44^{\circ} \%\right)$. mp $151 \sim 153^{\circ} \mathrm{C} . \quad[\alpha]_{\mathrm{D}}^{20}-88.2^{\circ} \quad\left(c=0.730, \mathrm{CH}_{3} \mathrm{OH}\right) . \quad$ IR $v_{\max }^{\mathrm{KBr}} \mathrm{cm}^{-1}: 1620,1510,1455,1360,1245,850,780,750$, 740. Found: C, 69.20; H, 5.83; N, 4.82. Calcd. for $\mathrm{C}_{33} \mathrm{H}_{33} \mathrm{~N}_{2} \mathrm{O}_{2} \mathrm{Br}: \mathrm{C}, 69.59 ; \mathrm{H}, 5.84 ; \mathrm{N}, 4.92$.

General procedure for asymmetric epoxidation. To a solution of substrate $(1.0 \mathrm{mmol})$, peroxide $(1.1 \mathrm{mmol})$ and phase transfer catalyst $(0.004 \sim 0.06 \mathrm{mmol})$ in toluene $(10 \mathrm{ml})$ was added $6 \mathrm{~N}-\mathrm{NaOH}(36 \mu \mathrm{l})$ at between -5 and $-10^{\circ} \mathrm{C}$, before the mixture was stirred for $20 \mathrm{hr}$. After this period, the reaction mixture was washed with water and dried over anhydrous sodium sulfate. After evaporating the solvent, the epoxide containing fraction was distilled by a Kugelrohr apparatus, and the product was isolated in pure form by preparative VPC. The \%e.e. was determined by its optical rotation, and was confirmed further by ${ }^{1} \mathrm{H}$ NMR analysis with $\mathrm{Eu}(\mathrm{tfc})_{3}$. Work-up for the epoxidation of menadione was conducted according to Wynberg. ${ }^{10)}$
Acknowledgment. We are gratefull to Professor Dr. Eckehard V. Dehmlow for his valuable discussions and advices.

\section{REFERENCES}

1) A. S. Rao, S. K. Paknikar and J. G. Kiritane, Tetrahedron, 39, 2323 (1983). C. H. Behrens and K. B. Sharpless, Aldrichim. Acta, 16, 67 (1983). B. E. Rossiter, "Asymmetric Synthesis," Vol. 5, ed. by J. D. Morrison, Academic Press Inc., New York, 1985, p. 194.

2) H. Wynberg and B. Greijdanus, J. Chem. Soc., Chem. Commun., 1978, 427. H. Wynberg and B. Marsman, J. Org. Chem., 45, 158 (1980).

3) S. Julia, J. Guixer, J. Masana, J. Rocas, S. Colona, R. Annuziata and H. Molinar, J. Chem. Soc., Perkin Trans. 1, 1982, 1317. S. Colona, H. Molinar, S. Banfi, S. Julia, J. Masana and A. Alvarez, Tetrahedron, 39, 1635 (1983).

4) J. P. Mazaleyrat, Tetrahedron Lett., 1983, 1243.

5) Y. Inouye, J. Oda and N. Baba, "Asymmetric Synthesis," Vol. 2, ed. by J. D. Morrison, Academic Press Inc., New York, 1985, p. 91. N. Baba, M. Amano, J. Oda and Y. Inouye, J. Am. Chem. Soc., 106, 1451 (1984). M. Amano, N. Baba, J. Oda and Y. Inouye, Bioorganic Chem., 12, 299 (1984). N. Baba, F. Hoshide, J. Oda and Y. Inouye, Israel J. Chem., 25, 236 (1985).

6) H. Hiemstra and H. Wynberg, J. Am. Chem. Soc., 103, 417 (1981).

7) V. Sprinzak, J. Am. Chem. Soc., 80, 5449 (1958).

8) Ref. 2. E. V. Dehmlow and S. S. Dehmlow, "Phase Transfer Catalysis," ed. by H. F. Ebel, Verlag Chemie, Weinheim, 1980, p. 46.

9) H. R. Williams and H. S. Mosher, J. Am. Chem. Soc., 76, 2985 (1954).

10) H. Pluim and H. Wynberg, J. Org. Chem., 45, 2498 (1980). 